\title{
Defining and Measuring the Library's Impact on Campuswide Outcomes
}

\author{
Bonnie Gratch Lindauer
}

\begin{abstract}
Accreditation agencies, higher education institutions, and professional organizations all emphasize the importance of measuring and assessing the impacts or effects of teaching, learning, and other valued institutional activities. Academic libraries, one of the key players in providing and structuring instructional resources and services, also are expected to document how their performance contributes to institutional goals and outcomes. Using accreditation and ACRL sectional standards/criteria, higher education outcomes assessment research findings and recent findings from performance effectiveness studies, this article identifies important institutional outcomes to which academic libraries contribute; describes specific performance indicators whose measures of impacts and outputs provide evidence about progress and achievement; and offers a conceptual framework of assessment domains for the teaching-learning library.
\end{abstract}

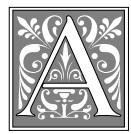

$\mathrm{n}$ increasingly important concern for academic librarians is how to document and measure the ways that the library, learning resources, and computer services units make a real difference in the academic quality of life for students and faculty. This concern was expressed clearly by Sarah M. Pritchard:

The future vitality of libraries in academia will be dependent on whether they can dynamically and continually prove their value to the overall educational endeavor. This value must be documented at a level that transcends specific formats of information, locations of collections and location of users, and that clearly links the investment in campuswide information resources to the effectiveness of particular disciplinary programs. ${ }^{1}$

Generally, academic librarians face two problems when trying to describe the impact of their services and resources on desired institutional outcomes and goals. First, they are not sufficiently strategic or externally focused when determining which measures to use as evidence of how the library affects educational outcomes. Second, they often do not organize their data and other supporting documentation in ways that are accessible or meaningful to academic administrators and accreditation teams, nor do they use language that reflects what is used in campuswide planning documents. Typically, all sorts of data are presented in

Bonnie Gratch Lindauer is Reference and Instruction Librarian at City College of San Francisco; e-mail: bgratch@ccsf.cc.ca.us. The author acknowledges the California Academic and Research Librarians Association for supporting this project with a research award. 
annual reports and program reviews, but they do not explicitly address how the library's resources and services make a qualitative difference to student learning, staff development, faculty scholarly activity, and other campuswide goals.

Motivated by the desire to improve the measurement and documentation of the impact of academic library's services and programs on institutional outcomes, the author seeks to (1) identify key institutional outcomes to which academic libraries contribute; (2) specify library performance indicators whose measures can provide a culture of evidence to document progress and contributions toward the realization of campuswide outcomes and goals; (3) offer a framework of assessment categories that emphasizes the teachinglearning role; and (4) build on the library effectiveness/quality knowledge base by pinpointing useful publications for measuring inputs and outputs. To accomplish these purposes, this article:

- summarizes some of the characteristics of the library effectiveness / quality literature;

- summarizes findings derived from reviews and analyses of a variety of authoritative sources that identify contemporary and emerging campuswide performance expectations for academic libraries;

- presents a framework of assessment categories that reflects a primary teaching-learning role;

- identifies specific key institutional outcomes and outputs, along with corresponding performance indicators, that academic libraries can use to describe and assess their impact;

- offers some practical concluding comments to assist librarians who want to connect their programs and services to broader campus educational goals and desired outcomes for self-studies, program reviews, and other assessment activities.

Thus, this article's contribution is threefold. First, taking a campuswide perspective, it advocates that the assessment of library performance should be defined and shaped by its connections and contributions to institutional goals and desired educational outcomes. Second, it proposes that assessment efforts and results be focused on the primary role of the teaching-learning library. And third, it identifies specific performance indicators for measuring and documenting the library's impact on key campuswide outcomes. The article does not include assessment issues related to making institutional comparisons because the author agrees with a recent Middle States Association of Colleges and Schools' publication that states that every institution must be considered within its own setting and not by comparison with general patterns or norms. ${ }^{2}$ Because this article's perspective is organizationlevel assessment, it excludes library suborganizational approaches. Also excluded are criteria and indicators dealing with cost and cost-efficiency and effectiveness. Readers are referred to Charles R. McClure and Cynthia L. Lopata for network efficiency indicators and to Paul B. Kantor and Frederick W. Lancaster for guidance and methods evaluating traditional library suborganizational services and resources. ${ }^{3}$

\section{Literature Review}

A great deal of literature exists on the models, performance criteria, measures, methods, and results of evaluation studies related to academic library effectiveness, efficiency, and quality of performance. In summary, the literature is devoted to two major concerns that are often combined in publications. The first concern centers on efforts to describe the determinants of effectiveness or qualitythat is, what is conceptually meant by quality or effectiveness so that it can be operationalized into performance criteria or other types of criteria to use for measurement purposes. The second concern focuses on the numerous attempts to describe specific measures and methods of collecting data. Indeed, there are several good publications that offer field-tested measures and data-gathering techniques 
to provide guidance in all aspects of measuring and evaluating inputs, processes, and outputs. ${ }^{4}$ However, almost none of these publications provides measures or methods for assessing the impact of academic libraries on campuswide educational outcomes. Overwhelmingly, the literature is internally focused, looking at the academic library as an overall organization or at one or more of its compo-

The teaching-learning role of academic libraries is well established, as are the expectations of accreditation agencies that libraries connect their evaluation of collections, resources, and services to educational outcomes.

nents or services. Except for the literature that looks at evaluating libraries as part of accreditation or as part of planning efforts, most of the literature on academic library effectiveness or quality does not take a campuswide view in relating library programs to campus outcomes. Instead, it has been concerned primarily with measuring and evaluating the quantity, effectiveness/quality, and efficiency of traditional academic library inputs (staff, budget, collections, facilities), processes (collection development, cataloging, management practices), and outputs (reference service, OPAC use, ILL/document delivery service). Most of this literature is well reviewed in publications by Rosemary DuMont and Paul F. DuMont, Deborah L. Goodall, Joseph A. McDonald and Linda B. Micikas, Sarah M. Pritchard, and Nancy A. Van House. ${ }^{5}$ Pritchard's review is particularly recommended for its coverage of fundamental concepts, its focus on assessment in higher education as a whole and ways that determinants of library quality should be linked to educational outcomes.

There is no shortage in the number of writers who have decried the redundancy coming from this forty-year-plus literature, particularly the lack of objective ways to measure and incorporate library value into processes such as academic accreditation and educational assessment. The common observation made in numerous publications is that what is most needed are performance indicators that demonstrate the academic library's impact on desired educational outcomes and methods to measure them.

However, some notable exceptions have looked at the academic library's connection to institutional outcomes such as student academic performance and faculty productivity. Ronald R. Powell's summary of these works includes the impact studies of several earlier researchers. ${ }^{6}$ The types of impacts discussed in these works are measures of academic library use and library skills instruction correlated to lower attrition rates, higher grades, higher GRE scores, student persistence, and savings in faculty time. Powell provides a list of several performance indicators of impact derived from his literature review (test scores, course evaluations, course grades, quality of papers) and recommends user panels for data collection because "they share some of the strengths of focus group interviews but go beyond them by being more longitudinal and comprehensive." 7

More recent is the major influence of the outcomes assessment movement. Fueled by state legislatures, this movement requires higher education institutions to provide evidence for what students have learned and how much, sometimes along with the costs of doing so. The primary change that outcomes assessment has caused, it seems, is to place responsibility on all institutional units for providing evidence of their contributions to desired educational outcomes and to incorporate outcomes assessment into organizational planning and improvement. Ralph A. Wolff, executive director of the Senior Colleges and Universities Commission of the Western Association of Schools and Colleges (WASC), calls for a "culture of evidence" in his writings describing a stronger instructional role for libraries. ${ }^{8}$ He stressed that assessment 
must reflect the library's relationship to the teaching and learning functions of the institution. He also has provided much useful guidance about improving library accreditation self-studies and has suggested needed measures that demonstrate library impact, such as usage data organized by academic programs; the role of the library in curricular development; evaluation of what students learn from bibliographic instruction programs; and the relationship of the library to campus information systems development. ${ }^{9}$ Thus, both the library effectiveness / quality literature and the higher education literature reflect the need for assessing outcomes. Although academic libraries contribute to various institutional outcomes, it is the impact of their instructional program that has been typically connected to student learning outcomes. ${ }^{10}$

Teaching library and information literacy skills is viewed as directly affecting student outcomes because these skills support such general/liberal education outcomes as critical thinking, computer literacy, problem-solving, and lifelong learning. In fact, although the teachinglearning role is not a new one for academic librarians, it has taken on a renewed importance, in part because of the effects of information technology on higher education and the leadership at national, state, and local levels of the information literacy movement. Indeed, it seems that the common denominator in the many publications describing the new and/or reshaped roles of the academic library is that of the teaching-learning library, defined by Carla J. Stoffle and Karen Williams as follows:

... it focuses on teaching as both a direct activity and a support activity for other disciplines; creates new knowledge packages and access tools; provides a physical environment that facilitates student and faculty research and collaboration; and provides access to resources that are the necessary underpinnings of the new learning environment. ${ }^{11}$
The teaching-learning role of academic libraries is well established, as are the expectations of accreditation agencies that libraries connect their evaluation of collections, resources, and services to educational outcomes. Although there are some useful suggestions from accreditation, outcomes assessment, and academic library effectiveness publications on how to assess the impact of libraries, what is lacking is the identification of a more comprehensive set of performance indicators linked to valued higher education outcomes. However, before presenting the findings from the content analyses and reviews, it is necessary to define some terminology.

\section{Review of Terminology}

What is the difference between performance measures and indicators? What is meant by "valued institutional outcomes"? Is the evaluation of library effectiveness the same as library quality or performance? Although some writers define performance measures more narrowly, the author has adopted the following definition by McClure and Lopata:

Performance measures are a broad, managerial tool that encompass measurement of inputs (indicators of the resources essential to provide service); outputs (indicators of the services resulting from the use of those resources); and impacts (the effects of these outputs on other variables or factors) ....12

Although the terms performance criteria, performance indicators, and performance factors are sometimes used interchangeably, the author uses criteria to mean guidelines or standards operationally employed as the basis for making a judgment or decision. Typically, these criteria are identified from a literature review or a survey of various user groups, and as a result of some selection process they represent traits or characteristics of libraries/librarians presumed to be desirable or impor- 
tant. Thus, they can be called performance indicators because their measures indicate something desired or important.

Throughout this article, the word outcomes is reserved for the realized goals valued by various campus constituents, also called stakeholders, and the word impact(s) is used for those direct effects the library has on institutional outcomes, or if more indirect, the enabling effects that contribute to these outcomes. Some researchers have further defined outcomes by involving higher education constituent groups to identify important outcomes. McDonald and Micikas explain that "valued institutional outcomes" are those that are perceived to be important by the key stakeholders of colleges and universities (students, faculty, and academic staff and administrators) as well as by the external professional culture (accreditation agencies and professional organizations) and society at large (political bodies and the marketplace). ${ }^{13}$ The terms evaluation and assessment are used interchangeably in this article, as are library effectiveness and $l i$ brary quality.

\section{Methods}

To identify valued institutional outcomes from key stakeholder groups, several literature reviews and content analyses were completed of the latest editions of regional accreditation standards, ACRL sectional standards, higher education outcomes assessment research, and academic library literature dealing with information literacy and changing roles. The author searched these various documents for language describing or implying enabling library services and resources that contribute to the achievement of expected or desired educational outcomes, thus making them prime candidates for developing performance indicators. She assumed that in addition to the higher education outcomes assessment sources, the regional accreditation standards would be authoritative for exposing institutional outcomes and ex- pected/required services and resources of academic libraries. Several research reports employing the Delphi survey technique were particularly useful because they reflected the views of large groups of key stakeholders on topics such as what college students should know and be able to do; what core information literacy skills are; and what instructional good practice criteria are. In addition to the sources mentioned above, performance indicators also were derived from reviews of library effectiveness research and performance evaluation manuals. Moreover, the author extracted ideas from publications discussing the emerging and future roles of largely digital libraries. For example, roles and functions that should be reflected in a library's performance criteria and indicators include: ${ }^{14}$

- creation and support of "holistic computing environments" that make the technology work for all users, regardless of location;

- delivery of around-the-clock reference and instructional services over the network;

- partnering across administrative lines for the improvement of services and resources;

- provision of improved electronic integrated library systems that emphasize direct user access to both full-text and bibliographic resources for resident and distance education learners;

- high-quality document delivery service;

- instructional design and production of teaching materials;

- creation of new knowledge packages and new access tools;

- improvement of campus understanding of, and participation in, local information policy development.

The results of the various reviews and analyses are presented next, organized by grouping selective findings from the regional accreditation and ACRL standards; higher education research on teachinglearning outcomes; and library effectiveness evaluation research and performance evaluation manuals. 


\section{Findings from the Regional Accreditation and ACRL Standards}

Five of the seven regional accreditation commissions' standards were revised within the past three to four years, and three were revised in $1996 .{ }^{15}$ With the exception of the North Central Regional Association, these documents contain separate sections dealing with library and learning resources and all but one define the "library" section's scope broadly to include learning resources such as instructional media centers, computer centers, museums, language labs, networks and telecommunications facilities. The regional accreditation standards do not explicitly describe many of the institutional outcomes to which academic libraries directly contribute, but they do contain statements in various sections that relate to library performance criteria, as well as clear statements about expected or required library outputs and inputs that support educational outcomes. Although the standards in the designated library section relate primarily to inputs such as collections, facilities, and staff, there are standards in most of the documents that relate to contemporary issues such as access versus ownership, distance education, information literacy, and the availability of suitable and sufficient information technology. One overall theme is the importance of use over resource acquisition. For example, "the size of collections and the amount of money spent do not ensure adequacy. Of more importance are the quality, relevance, accessibility, availability and delivery of resources and services, and their actual use by students, regardless of location."16 The following themes reflect institutional expectations of libraries, thus making them key areas for the identification of performance measures that can generate data to be part of the culture of evidence.

Access, availability, and use: All six documents have a section heading or at least one entire paragraph of text devoted to access and availability, frequently making connections to use. Statements dealing with off-site programs, remote access, or distance learning support are often included in the access and availability sections. For example, "Because adequate library and other learning resources and services are essential to teaching and learning, each institution must ensure that they are available to all faculty and enrolled students wherever the programs or courses are located and however they are delivered." ${ }^{17}$

Collections and learning resources: All six documents connect collections to the library's primary goal of supporting teaching and learning, and all use language to include a broad understanding of "collections." Several directly connect resources to access and use. For example: "Library/learning resources must be in reasonable proportion to the needs to be served, but numbers alone are no assurance of excellence. Of more importance are the quality, accessibility, availability and delivery of resources on site and elsewhere; their relevance to the institution's current programs; and the degree to which they are actually used." 18

Information literacy: All the documents contain some type of statement about orientation, instruction, and/or training within the library section of the standards, usually connecting the value of this service to students becoming effective and/or independent learners and increasing their use of library and network resources. But only one document contains language in both library and educational program sections. The following text from the educational program section connects information technology facility to educational outcomes: "The general education program provides the opportunity for students to develop the intellectual skills, information technology facility, affective and creative capabilities, social attitudes, and an appreciation for cultural diversity that will make them effective learners and citizens."19

Information technology: Academic computing is included within the scope of the library section of the standards in all but two of the documents (Middle States and Southern), where there are 
separate sections in the standards for academic computing and information technology. All the documents make references to having appropriate and sufficient information technology available, usually connecting it to improving or extending access. An example of a strong statement follows: "Institutions must provide the means by which students may acquire basic competencies in the use of computers and related information technology resources ... reliable data networks should be available so that faculty, students and staff may become accustomed to electronic communication and familiar with accessing national and global information resources. There must be provisions for ongoing training of faculty and staff so that they may make skillful use of appropriate application software." 20

Outcomes assessment: All seven of the regional accreditation commissions have included in their standards, and/or in more recent supplemental publications, statements about the importance of student outcomes assessment. Common to most of the documents are statements requiring documentation of an assessment plan based on the institutional mission and academic program goals; ongoing assessment that involves various stakeholders; use of a variety of assessment measures and methods, including making use of already collected institutional data; and evidence that the results of assessment are being used for program improvement.

Collaboration with faculty and other academic staff: All six documents include statements in the library section and/or in another section of the standards about librarian collaboration with faculty or other academic staff. The most common type of collaboration specified is for collection development.

Staff: All six documents have a section or paragraph of the standards about professional staff, and some also discuss support staff. For example, "Librarians and other resources center staff must demonstrate their professional competence on the basis of criteria comparable to those for other faculty and staff. . . ."21
Just as important is the text related to libraries and information technology in other sections, such as the educational program section. All but one association's standards (New England) include some reference to libraries in this section, stating that either library resources must be sufficient to support the academic programs or the use of resources is required or expected. Other text in this section supporting the library's direct role in teaching and learning refers to academic programs that demonstrate innovative teaching methods by the use of library and media resources and text about cooperative relationships, such as: "Librarians must work cooperatively with faculty and other information providers in assisting students to use materials." 22

Comparing the three ACRL sections' latest standards/criteria documents (University Libraries Section, 1989; College Libraries Section, 1995; and the Community and Junior Colleges Libraries Section, 1994) to the regional accreditation standards reveals many commonalties and some significant differences. All three documents parallel the regional accreditation standards by including a section heading and/or at least one full paragraph of text devoted to bibliographic instruction or information literacy; cooperative relationships on and off campus and resourcesharing agreements; access and availability issues related to collections and resources; and assessment or evaluation. The following examples illustrate how some of these ideas are represented.

The three ACRL section documents contain several statements relating to collaboration and cooperation with disciplinary faculty and other academic staff, but only the University Library Section (ULS) document has an entire section devoted to this theme. Like some of the regional accreditation documents, it calls for the establishment of a relationship between the library and the computer and telecommunications services. Also, all three documents contain language about the importance of evaluation, but only the Community and Junior Colleges Librar- 
ies Section (CJCLS) and the ULS documents describe the need for different measures. In fact, the ULS document provides useful guidance about the process of evaluation and offers specific criteria that academic libraries might use. The CJCLS text makes the strongest connection between libraries and institutional impact:

If institutional effect is measured in terms of student success in grades, credit and completion and transfer rates, then learning resource standards based on circulation statistics, book counts and other traditional measures may not be relevant because they are limited in detailing the direct impact of learning resource programs in effecting successful learning outcomes. Learning resource effectiveness measures should rely on the relational attributes of the program which directly impact learning attained by students. ${ }^{23}$

The analysis and comparison to regional standards suggest that although there is overlap with the regional accreditation standards, overall the ACRL section standards reflect a more internal orientation. That is, they focus primarily on the inputs, processes, and outputs considered necessary for high-quality libraries and learning resources, with little text devoted to broader roles or connections of library use to student learning or other institutional outcomes. The major exceptions to this observation are the ULS and CJCLS documents that include some language about broader roles in the role and purpose sections.

Also lacking is the prominence given to the kinds of statements found in several of the regional accreditation documents which express the importance of access and delivery of resources in all formats to all locations, on-site or elsewhere. Only the ULS document has a separate section labeled "Access," which "implies the delivery of information, whether in printed or electronic format, by the library to the user at the user's location." ${ }^{24}$ However, there are statements in the College Libraries Section and CJCLS documents about providing access to off-campus programs. In general, the accreditation standards seem to do a better job than the ACRL standards of connecting the use of library, learning, and network resources and services to student educational outcomes.

\section{Findings from Higher Education Research on Teaching-Learning Outcomes}

Many of the teaching-learning outcomes included in this section come from major higher education researchers and centers, such as Alexander Astin; Peter Ewell; the National Center on Postsecondary Teaching, Learning and Assessment; and the National Center for Higher Education Management Systems. Perhaps not surprisingly, the author found that in most cases empirical research connecting college students' experiences and outcomes with specific campus services and resources did not include any mention of libraries/learning resource centers. One has to look closely to find outcomes that, though not directly stated, suggest the involvement of academic libraries.

Alexander Astin's longitudinal research on freshmen and undergraduates is well known and frequently cited. His book, What Matters in College? Four Critical Years Revisited, focuses on student outcomes and how they are affected by the college environment. Several findings reported in Astin's review article in Liberal Education are noteworthy:

The single most powerful source of influence on the undergraduate student's academic and personal development is the peer group.... The amount of interaction among peers has far-reaching effects on nearly all areas of student learning and development. . . . Time spent studying and doing homework had significant effects on more than twothirds of the eighty-two outcome measures (e.g. retention, graduating 
with honors, enrollment in graduate school, and standardized test scores). ${ }^{25}$

In addition to the importance of time spent studying and peer group interaction are other findings highly associated with student academic development. Many of these can be connected to libraries, such as participating in college internship programs; participating in racial/ cultural awareness workshops; doing independent research projects; making class presentations; and taking essay exams. ${ }^{26}$

\section{One has to look closely to find outcomes that, though not directly stated, suggest the involvement of academic libraries.}

Several government-sponsored research studies connected to National Education Goal Six (formerly numbered Goal Five) offer significant findings of relevance to the design of student information literacy performance outcomes and faculty good practice instructional criteria. The National Assessment of College Student Learning has produced several studies, but the one of most interest is the 1995 report Identifying College Graduates Essential Skills in Writing, Speech, Listening and Critical Thinking. What follows are examples of specific skills or expected performance outcomes of relevance to academic librarians which a consensus of stakeholder groups considered to be important or very important for college graduates to possess. Although these skills are not new to librarians involved with information literacy instruction, the fact that they have been articulated at a national level increases their credibility at all levels and their importance for instructional development and assessment. ${ }^{27}$ For example:

Pre-writing skills: College graduates should be able to research their subject and identify problems to be solved that their topic suggests. 1.a.
Locate and present adequate supporting material.

Critical Thinking Skills: Evaluation Skills: The ability to evaluate the credibility, accuracy and reliability of sources of information was cited as extremely important.

Critical Thinking Skills: Inference Skills: Collecting and Questioning Evidence: Determine what is the most significant aspect of a problem or issue that needs to be addressed, prior to collecting evidence. Determine if one has sufficient evidence to form a conclusion. ${ }^{28}$

Another research project connected to the same National Education Goal explored the feasibility and utility of establishing good practice indicators in undergraduate instruction as supplementary data to student outcomes data. Findings from this project are important to librarians and others who teach or conduct training because they focus on assessing the instructional planning and delivery practices of librarians, which is after all the other side of the coin of assessing student learning and performance. The report synthesizes an extensive review of the empirical research in this area. Although there are many useful findings of interest to instructional services librarians, what follows are selected findings based on robust and strong data correlations thought to be highly relevant for selecting performance measures and types of methods to assess teaching practices:

Indicators based on student behaviors and active learning instructional processes gathered through student and faculty questionnaires are most promising for development as potential national indicators, supplemented by transcript studies and assessments of typical college examinations and assignments. . . . Overall the bulk of evidence appears to support the util- 
ity and consistency of data obtained from student self-reports. ${ }^{29}$

For broader critical thinking and problem-solving abilities ... three distinct kinds of in-class activities made a difference in promoting thinking skills—student discussion, an explicit emphasis on problemsolving procedures and applications, and stressing the use of verbalization and modeling strategies in which students think through a problem. ${ }^{30}$

\section{Library Effectiveness Criteria and Performance Indicators from Research and Evaluation Manuals}

The following sources dealing with organization-level evaluation of academic libraries are briefly profiled because even though few impact measures were discovered from the author's careful review, they illustrate improved approaches for defining essential performance criteria. The selection of sources that follow was based on two criteria: (1) empirical studies using a multiple stakeholder or constituent satisfaction approach; and (2) performance evaluation manuals that have been field-tested or developed with broad professional input.

More recent studies of library effectiveness at the organizational level have employed different approaches to measuring effectiveness and service quality, which are based on the research of Nancy A. Van House and Thomas Childers and others. ${ }^{31}$ Although none of these multiple stakeholders or constituent satisfaction studies address the impact of academic libraries, they seem to offer improvements over previous approaches to determining what should be measured. For example, user validation of the most important indicators of effective performance is provided; the methods are theoretically grounded, yielding reliable and valid test instruments; and librarians can select locally appropriate performance indicators for replication at their institutions.
Rowena Cullen and Philip Calvert's work, carried out in all New Zealand academic libraries, included random samples of all key stakeholder groups to rate the importance of ninety-nine performance indicators. Figure 1 presents those indicators rated 3.8 or higher by all six and by five of the stakeholder groups, using a scale where five is "very important." 32

Tobin de Leon Clarke's research and resulting Output Measures Manual for California community college library/ learning resource centers was based on a survey of all California community college libraries/learning resource centers. Using resource center administrators to rate potential output measures, she identified twelve useful measures and obtained data on how such measures would be used at a local level. Only one impact measure was included, which could be used at institutions where separate information literacy/library research courses are offered: "library skills course completion rate in proportion to the FTE student population." 33

McClure and Lopata's qualitative research on assessing academic networking resulted in the publication of Assessing the Academic Networked Environment: Strategies and Options. This much-needed manual provides strategies, performance measures, and procedures to document the extent, effectiveness, efficiency, and, to a lesser degree, the effects of the academic networked environment. Derived from their research findings is a description of the constituent elements of the academic networked environment and this conclusion: "An adequate network infrastructure is believed to be essential to attract and retain high quality faculty and students." 34 Depending on local educational goals, the following are potentially useful impact measures stated in, or rephrased from, this source:

\section{Teaching-learning indicators:}

- percent of all students enrolled in distance learning classes in a given semester and distance learning student GPA compared tonon-distance-learning studentGPA; 


\section{FIGURE 1 \\ Cullen and Calvert Study: Performance Indicators for Which Group Means Were 3.8 or Higher*}

I. Management/Administration

+Match of goals and objectives to user group needs (4.18)

+Competence of library management (4.32)

\#Total amount of library budget (4.06)

II. Collections and Learning Resources Adequacy

\# Provision of multiple copies of items in high use (4.12)

+ Currency of library materials (4.15)

+ Flexibility of budget to respond to new subject areas (4.01)

+ Speed of acquisition of new materials (4.01)

+Adequacy of library collection compared with other institutions (3.84)

\# Frequent evaluation of collection (3.82)

III. Access, Availability, and Use

+ Match of hours open with user needs (4.33)

+ Proportion of library materials listed on computer catalog (4.33)

+Proportion of items wanted by user finally obtained (4.24)

+ Access to library catalogues, via networks throughout the campus (4.06)

+ Ease of use of public catalogs (4.09)

\# Speed and accuracy of reshelving of materials (4.1)

\# Provision made for disabled users (4.17)

\# Access to CD-ROMs, databases, via networks throughout campus (3.94)

\# Speed of recall of items out on loan requested by other users (3.95)

\# Speed of recall of reserved items (3.85)

\# Availability of periodical indexes on CD-ROM (3.85)

IV. Instructional and Research Services

+ Expert staff assistance to users available when needed (4.53)

+ Helpfulness, courtesy of staff (4.50)

+ Expertise of reference staff $(4.38)$

+ Availability of reference staff when needed (4.18)

+ Success in answering reference questions (4.15)

V. Facilities/Infrastructure

+ Quietness of study environment (4.18)

+ Number of seats per full-time student equivalent (4.06)

+Equipment (e.g. photocopiers) kept in service by good maintenance (4.16)

* Source: Cullen and Calvert academic libraries data. The + before an indicator indicates all six groups had means of 3.8 or higher out of a possible 5 , and a \# before an indicator shows that five of the six groups' means were 3.8 or higher.

- percent of all student, faculty, and librarian respondents who rate the usefulness of having access to the OPAC and other online library services from outside the library as "very useful" for completing their class assignments, research, teaching and design of class assignments, job-related activities, and professional development;
- percent of student, faculty, and librarian respondents who indicate that student use of networked information resources has positively affected the quality of student papers / projects;

- percent of students who indicate to what extent and how the use of aspects of particular network resources have af- 


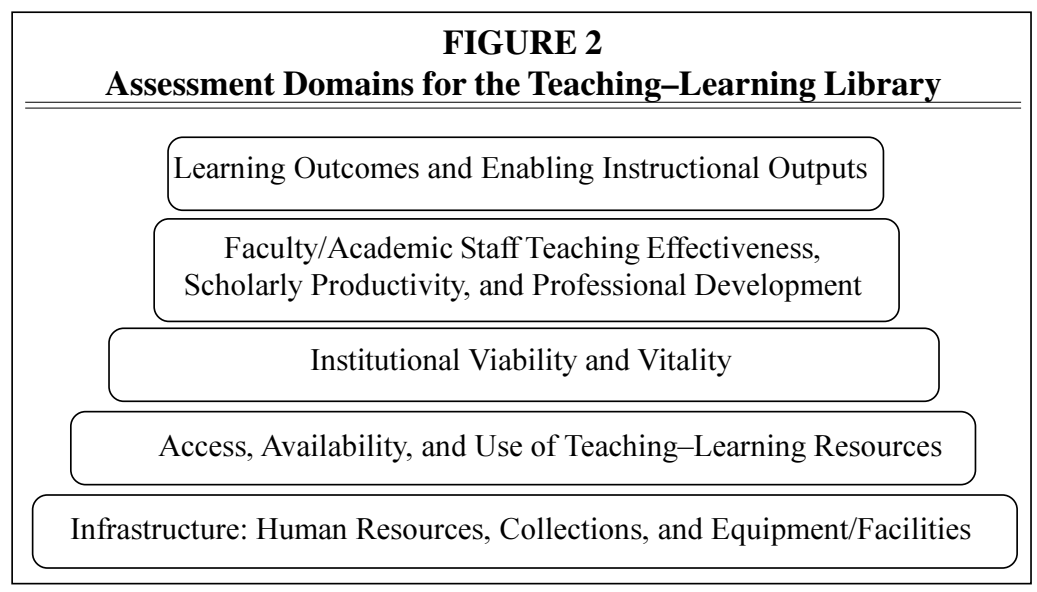

fected their learning specific information literacy skills;

- longitudinal data for same sample of students comparing freshmen and seniors rating their confidence of ability to be independent, electronic information seekers and evaluators;

- percent of classes within academic programs requiring networked-based assignments.

2. Faculty productivity indicators: Percent of faculty indicating that in the past two years their use of networked information resources has resulted in desirable outcomes such as obtaining funding and publishing research/scholarly articles.

3. Recruitment indicators: Percent of new faculty and professional staff hires and new students and their ratings of the extent to which specific network applications affected their decision to come to the institution. ${ }^{35}$

\section{Performance Evaluation Manuals}

In the past ten years, there have been various initiatives to advance the measurement of library and network effectiveness/quality by the publication of several manuals. The books by Van House, Weil, and McClure; McClure and Lopata; and Roswitha Poll were sponsored by major professional organizations, and were designed for use in all academic libraries and field-tested. ${ }^{36}$ They describe and provide detailed guidance on data collection for a variety of measures of effectiveness (and cost-benefit/efficiency measures in the McClure and Lopata manual), but only the McClure and Lopata manual includes some impact measures. All include user satisfaction measures, materials availability and use measures, facilities use measures, and some public service measures. A comparison of the types of performance measures included in these manuals with those identified by Cullen and Calvert's stakeholder research reveals that there are several equivalent indicators, as well as unique ones from Cullen and Calvert's findings, such as match of goals and objectives to user group needs; proportion of library materials listed on OPAC; access to library catalogues and other databases via network; provision made for disabled users; expert staff assistance to users available when needed; and quietness of study environment.

The findings described above from multiple stakeholder research studies and field-tested manuals reveal what academic library constituent groups and respected colleagues perceive to be important input and output performance indicators. As such, they are candidates for key enabling indicators, those that make it possible for the achievement or success of valued institutional outcomes such as faculty scholarly and research productivity and student development of information literacy skills. Moreover, it is clear that accreditation standards require or expect good performance on these types of measures. 


\section{Conceptualizing Outcomes-Based Assessment}

The next section provides both a conceptual framework to structure assessment efforts and a listing of specific outcomes, outputs, and inputs connected to performance indicators that will generate evidence of progress toward and/or accomplishment of valued campuswide outcomes. Figure 2 presents a framework of five assessment domains the author suggests are important assessment categories that all academic libraries should include in their assessment plans. It depicts the foundational role that infrastructure inputs play, as opposed to the primary role they have been known for in past library effectiveness evaluation studies. It also illustrates the priority of student learning outcomes by placing them at the top. Another intent of this schema is to communicate that each layer depends on the layers under it, although in reality there is an interplay of performance indicators represented by the categories.

\section{Connecting Institutional Outcomes and Outputs to Performance Indicators}

Using the findings from all the sources analyzed, figures 3 through 5 (pp. 564570) reflect the five assessment domains and contain outcome/output statements and salient performance indicators. McClure and Lopata's publication, Assessing the Academic Networked Environment, is credited for many of the network-related performance indicators listed in these figures. Although a library's selection of outcome statements and performance indicators must be based on its institution's mission, goals, and planning documents, all libraries might find useful some of the outcome statements and performance indicators in figures 3 through 5. They reflect what has been documented as valued by academic stakeholders in three or more sources. Many variables other than the indicators listed in these figures lead to the accomplishment of the specified campuswide outcomes, but this article, understandably, is limited to the identification of only library and network contributions.

The usefulness and benefits of figures 3 through 5 are to be found in the systematic linkages of specific performance indicators to important campuswide outcomes and outputs, but, admittedly, the author has not tried to be comprehensive. The emphasis of this article has been on identifying teaching-learning outcomes, outputs, and performance indicators because they are at the heart of how the library makes a difference to its institution. Of equal value is the inclusion of good practice criteria for teaching effectiveness, reminding the reader that librarian-instructors need to be evaluated using many of the same performance indicators as disciplinary faculty because good teaching enables effective learning. In addition, representative performance indicators are included that were mentioned in standards and multiple stakeholder studies for access, use, infrastructure, and institutional vitality. Both quantitative and qualitative types of measures are included because building a culture of evidence involves a cumulative, multimethod approach. Although data collection methods are not specified, the performance indicators suggest certain methods and readers can find guidance in several of the previously referenced performance evaluation manuals.

The following example illustrates and clarifies how these tables might be used. A library preparing a self-study for an upcoming accreditation visit might begin by comparing the outcome statements found in figures 3 and 4 with outcomes articulated in its campus strategic plan or educational goals and priorities documents. As a result, additional outcome statements might be identified and/or modification of the language used in the figures to reflect local preferences. The idea is to develop library outcome statements that reflect desired institutional outcomes and priorities as closely as possible, as well as drafting those that are important to librarians and accreditation teams (e.g., "All graduates are informa- 
tion literate," or "The campus environment is conducive to learning"), but may not be contained in local documents. Within these broad outcome statements, librarians then begin to specify the enabling outputs and inputs (resources, materials, facilities, services) that their libraries provide and to determine performance indicators that will actually be used for data collection and documentation. As figure 3 illustrates for some student learning outcomes such as \#1, the library's contributions can be captured by performance measures that directly indicate progress (or lack of progress) and extent of accomplishment of the desired student learning outcome. However, for other outcomes, such as \#2, the linkage is indirect, and enabling outputs and inputs must first be identified for which measurable library support can be documented that makes essential contributions to the accomplishment of the outcome. This process should be carried out collaboratively with involvement, or at least input, from academic administrators, faculty, and students. Perhaps the members of a library advisory committee could be used for this task.

Clearly, outcome statement \#2 in figure 3 is extremely broad (and could be rephrased for graduate programs), yet it is predictably part of every institution's desired outcomes. The value of the eight "enabling instructional outputs and good practice criteria" is that, taken together, they define the library-related components of necessary resources, services, and facilities that make it possible for the accomplishment of this broad outcome. Indeed, the challenge to librarians is to make this connection clear by explicitly linking the enabling outputs and inputs to the desired outcome and to document the amount, quality, and effects of use of these (or other) essential factors. Throughout this process, care should be taken to use language from campus or higher education documents, not library jargon. Moreover, another challenge is to organize and present the data meaningfully for the target audience of faculty and academic administrators. Typically, library statistics are not kept or organized by academic programs, but to document the effects on students in particular academic divisions, whenever possible data can be organized in that way. Use of the performance indicators will generate data and

\section{One of the main points to be drawn from this article is that the assess- ment of library performance should be defined and shaped by its connections and contributions to institutional goals and desired educational outcomes.}

other types of documentation (such as copies of assessment plans) that describe to what extent and with what results the library's inputs and outputs (collections, electronic resources, services) have contributed to progress and/or accomplishment of these enabling outputs and practices.

\section{Conclusions}

Academic libraries, computer/information technology units, and their staffs do make a significant difference in the quality and outcomes of learning and teaching. Sometimes, though, librarians are so involved in daily operations that assessment and providing evaluative information on a regular basis for themselves and their constituents take a low priority. Only a scheduled accreditation visit or campus program review causes a change in priorities. One of the main points to be drawn from this article is that the assessment of library performance should be defined and shaped by its connections and contributions to institutional goals and desired educational outcomes. Thus, rather than continuing to generate potentially irrelevant data, librarians, in collaboration with faculty in the disciplines and other academic staff, need to define for their institutions the key functions and resources perceived to be directly (or indirectly) linked to valued outcomes, such as student learning, teaching, and scholarly activity. Moreover, librarians need to specify indicators of performance that would generate needed and accept- 
able data and other forms of documentation. Although it is always desirable to obtain data that attempt to "prove" that such and such an effect resulted from such and such cause or intervention, the author agrees with many higher education research findings uncovered in her literature review that confirm the reliability of student self-report data and other types of qualitative data that together can be used to demonstrate impact.

Working cooperatively to define the performance indicators and key outputs need not only occur as a separate activity at program review or accreditation times but, rather, can be part of all ongoing committee work, such as collection development, curriculum planning, and information technology planning. Finally, this type of dialogue should result in preferred groupings and presentation of both quantitative and qualitative data that will form the culture of evidence for all stakeholders.

This article has tried to facilitate such a process by offering a framework of assessment categories for academic libraries that reflects valued institutional outcomes found in a variety of publications and by providing examples of library performance indicators whose measures form part of a culture of evidence that documents progress and contributions toward the realization of desired outcomes. Although it is expected that institutional differences will lead to the development of other performance criteria and indicators, the assessment domains, or their equivalents, are important for all institutions. Particularly important is the emphasis on the teaching-learning outcomes to which the library contributes, such as teaching students to be information literate, training staff to use technology, and the library's role in the development of new knowledge or information-retrieval products. These are active roles, sometimes unique leadership roles, for which the results of performance assessment can be directly linked to undergraduate and graduate learning outcomes. By identifying those indicators found to be connected to institutional outcomes, the author hopes to have clarified how library services, human and material resources, and facilities can be defined and measured to document contributions to these outcomes. Also, by recommending specific performance evaluation manuals, the author has attempted to build on the existing library and network effectiveness knowledge base.

In summary, these points remain essential to the improvement of assessing impacts and outputs:

- In collaboration with other key constituent groups, a library assessment plan should be developed that focuses on performance indicators which contribute to valued institutional outcomes and outputs. This may require that decisions be made to stop certain types of data collection so that time and resources are available for new data collection. It also means that changes may be needed in the types of questions asked of users and in the unobtrusive ways that computerized systems can document use.

- Other assessment instruments and opportunities on campus should be sought where aspects of library performance can be included, such as senior or alumni surveys or focus groups.

- Benchmark data should be established for appropriate performance indicators and progress, change, and achievement documented as part of the culture of evidence. Lack of progress also can be connected to fiscal or other lacks in essential inputs so that unmet or unsatisfied demand/needs might be better explained.

- Relevant, available institutional and library data should be inventoried and used to complement other data collection methods so that a multimethod approach is used.

Data and findings should be organized and presented in ways that are more meaningful to faculty and academic administrators, such as grouping data items by academic program or broad disciplines and describing how students benefit. 
On a broader, more external level, academic librarians can provide leadership to further improve the assessment of their libraries. They can become more familiar with accreditation standards and be part of their revision so that explicit language might be included about the library's instructional role and the need for information literacy as an undergraduate outcome. ${ }^{37}$ Librarians can work to revise ACRL standards so that they reflect the emphases found in current accreditation standards and other higher education publications, such as demonstrating library/network use and its connection to teaching-learning outcomes and the instructional and technology development roles contributed by librarians to valued institutional outcomes.

Clearly, the time is ripe for on-campus and broader professional initiatives to emphasize the measurement and description of the extent and effects on teachinglearning outcomes of library activities such as information literacy programs; course/curricular development practices and teaching methods; creation of learning opportunities via programming, physical or virtual exhibits, online tutorials, and customized Web-based information resources; and collaborations with disciplinary faculty and other academic staff in technology planning and the development of instructional innovations and new knowledge or access products. Assessing impact becomes a way of organizational thinking about how academic libraries are linked to the overall educational enterprise. The resulting linkages, relationships, and benefits to the institution strengthen and help transform the library for the twenty-first century.

\section{NOTES}

1. Sarah M. Pritchard, "Determining Quality in Academic Libraries," Library Trends 44 (winter 1996): 591.

2. Guidelines for Librarian Evaluators (Philadelphia: Commission on Higher Education, Middle States Association of Colleges and Schools, 1997), 1.

3. See Paul B. Kantor, Objective Performance Measures for Academic and Research Libraries (Washington, D.C.: ARL, 1984); Charles R. McClure and Cynthia L. Lopata, Assessing the Academic Networked Environment: Strategies and Options (Washington, D.C.: Coalition for Networked Information, 1996); Frederick W. Lancaster, If You Want to Evaluate Your Library, 2nd rev. ed. (London: Library Association Publishing, 1993).

4. For example, see Steve Morgan, Performance Assessment in Academic Libraries (New York: Mansell, 1995); Roswitha Poll, ed., Measuring Quality: International Guidelines for Performance Measurement in Academic Libraries (Munchen: K.G. Saur, 1996); Patricia A. Sacks and Sara L. Whildin, Preparing for Accreditation: A Handbook for Academic Librarians (Chicago: ALA, 1993), 39-74; Nancy A. Van House, Beth T. Weil, and Charles R. McClure, Measuring Academic Library Performance: A Practical Approach (Chicago: ALA, 1990).

5. For example, see Rosemary DuMont and Paul F. DuMont, "Measuring Library Effectiveness: A Review and an Assessment," in Advances in Librarianship, vol. 9, ed. Michael H. Harris (New York: Academic Pr., 1979), 103-141; Deborah L. Goodall, "Performance Measurement: A Historical Perspective," Journal of Librarianship 20 (1988): 128-144; Joseph A. McDonald and Lynda B. Micikas, Academic Libraries: The Dimensions of Their Effectiveness (Westport, Conn.: Greenwood Pr., 1994); Pritchard, "Determining Quality in Academic Libraries," 572-594; Nancy A. Van House, “Output Measures in Libraries," Library Trends 38 (fall 1989): 268-279.

6. For example, see Jane E. Hiscock, "Does Library Usage Affect Academic Performance?" Australian Academic and Research Libraries 17 (1986): 207-14; Patricia B. Knapp, The Monteith College Library Experiment (New York: Scarecrow Pr., 1966); Lloyd A. Kramer and Martha B. Kramer, "The College Library and the Drop-out," College \& Research Libraries 29 (1968): 310-12; Felix Snider, "The Relationship of Library Ability to Performance in College" (Ph.D. diss., Univ. of Illinois, Urbana-Champaign, 1965).

7. Ronald R. Powell, "Impact Assessment of University Libraries," Library and Information Science Research 14 (1992): 254.

8. Ralph A. Wolff, "Using the Accreditation Process to Transform the Mission of the Library," New Directions for Higher Education 90 (summer 1995): 79. 
9. —_ "Rethinking Library Self-Studies and Accreditation Visits," in The Challenge and Practice of Academic Accreditation: A Sourcebook for Library Administrators, ed. Edward D. Garten (Westport, Conn.: Greenwood Pr., 1994), 125-138.

10. For example, see D. W. Farmer and Terrence F. Mech, eds., 'Information Literacy: Developing Students as Independent Learners," New Directions for Higher Education 78 (1992); Arlene Greer, Lee Weston, and Mary Alm, "Assessment of Learning Outcomes: A Measure of Progress in Library Literacy," College $\mathcal{E}$ Research Libraries 52 (Nov. 1991): 549-557.

11. Carla J. Stoffle and Karen Williams, "The Instructional Program and Responsibilities of the Teaching Library," New Directions for Higher Education 90 (summer 1995): 64.

12. McClure and Lopata, Assessing the Academic Networked Environment, 5.

13. McDonald and Micikas, Academic Libraries, 36.

14. These roles and functions have been drawn primarily from Chris D. Ferguson and Charles A. Bunge, "The Shape of Services to Come: Values-based Reference Service for the Largely Digital Library," College E Research Libraries 58 (May 1997): 252-265; Stoffle and Williams, "The Instructional Program and Responsibilities of the Teaching Library," 63-74.

15. Although there are six regions, there are seven accrediting higher education commissions because the Western Association of Schools and Colleges (WASC) has one for community colleges and one for senior colleges and universities. The North Central Association lacks a designated section for libraries/learning resources within the 1996 "Criteria for Accreditation," but it does include library requirements in the "General Institutional Requirements" that describe threshold-level requirements for affiliation with the commission. Therefore, in most cases, the analysis was based on these six documents: Characteristics of Excellence in Higher Education: Standards for Accreditation (Philadelphia: Commission on Higher Education of the Middle States Association of Colleges and Schools, 1994); Standards for Accreditation (Winchester, Mass.: Commission on Institutions of Higher Education, New England Association of Schools and Colleges, 1992); Accreditation Handbook (Seattle: Commission on Colleges, Northwest Association of Schools and Colleges, 1996); Criteria for Accreditation (Decatur, Ga.: Commission on Colleges, Southern Association of Colleges and Schools, 1996); Handbook of Accreditation (Oakland, Calif.: Accrediting Commission for Senior Colleges and Universities, Western Association of Schools and Colleges, 1988); Handbook of Accreditation and Policy Manual (Santa Rosa, Calif.: Accrediting Commission for Community and Junior Colleges, Western Association of Schools and Colleges, 1996).

16. Southern Association of Colleges and Schools, Criteria for Accreditation, 5.1.1.

17. Ibid.

18. Middle States Association of Colleges and Schools, Characteristics of Excellence in Higher Education, 15.

19. Western Association of Schools and Colleges, Commission for Community and Junior Colleges, Handbook of Accreditation, 4.C.3.

20. Southern Association of Colleges and Schools, Criteria for Accreditation, 5.3.

21. Middle States Association of Colleges and Schools, Characteristics of Excellence in Higher Education, 16.

22. Southern Association of Colleges and Schools, Criteria for Accreditation, 5.3.

23. "Standards for Community, Junior and Technical College Learning Resources Programs," College \& Research Libraries News 55 (Oct. 1994): 572-73.

24. "Standards for University Libraries: Evaluation of Performance," College E Research Libraries News 50 (Sept. 1989): 684.

25. Alexander Astin, "What Matters in College," Liberal Education 79 (fall 1993): 7.

26. Ibid.

27. In fact, several other significant publications have been penned by librarians that identify desired student outcomes and skills related to information literacy. For example, see Christina S. Doyle, Outcome Measures for Information Literacy within the National Education Goals of 1990: Final Report to the National Forum on Information Literacy - Summary of Findings 1992, ERIC, ED 351033; Jeremy J. Shapiro and Shelley K. Hughes, "Information Technology as a Liberal Art: Enlightenment Proposals for a New Curriculum," Educom Review 31 (Mar./Apr. 1996): 31-35; Susan C. Curzon and Work Group on Information Competence, "Information Competence in the California State University System: A Report" (Commission on Learning Resources and Instructional Technology, California State University System, Dec. 1995), photocopy.

28. Elizabeth A. Jones, National Assessment of College Student Learning: Identifying College Graduates' Essential Skills in Writing, Speech and Listening, and Critical Thinking: Final Project Report (Washington D.C.: U.S. Department of Education, 1995), 39, 136, 142.

29. A Preliminary Study of the Feasibility and Utility for National Policy of Instructional "Good Practice" Indicators in Undergraduate Education: Contractor Report (Washington, D.C.: Office of Educational Research and Improvement, U.S. Department of Education, 1994), 1, 24.

30. Ibid., 17. 
31. For example, see Nancy A. Van House and Thomas Childers, "Dimensions of Public Library Effectiveness II: Performance," Library and Information Science Research 12 (1990): 131-152; Rowena Cullen and Philip Calvert, "Stakeholder Perceptions of University Library Effectiveness," Journal of Academic Librarianship 21 (Nov. 1995): 445; McDonald and Micikas, Academic Libraries; Danuta A. Nitecki, "Changing the Concept and Measure of Service Quality in Academic Libraries," Journal of Academic Librarianship 22 (May 1996): 181-190.

32. The author is indebted to Rowena Cullen for providing the mean scores from each of the six stakeholder groups for all ninety-nine indicators, which allowed the author's analysis and presentation of data for figure 1. Using 3.8 as the cutoff was selected because it reveals more than the top twenty ranked indicators from the Cullen and Calvert article but still honors what they found about the small differences in ranking not being significant in the middle of the ranked lists.

33. Tobin de Leon Clarke, "Output Measures for Evaluating the Performance of Community College Learning Resources Programs: A California Case Study," in Advances in Librarianship, vol. 17, ed. Irene P. Godden (New York: Academic Pr., 1993), 199.

34. McClure and Lopata, Assessing the Academic Networked Environment, 2.

35. Ibid., 23-54.

36. Van House, Weil, and McClure, Measuring Academic Library Performance; McClure and Lopata, Assessing the Academic Network Environment; Poll, Measuring Quality.

37. The California Academic and Research Librarians Association Task Force to Recommend an Information Literacy Standard to WASC submitted its work to both of WASC's higher education accrediting commissions in fall 1997. As of July 17, 1998, these two documents can be accessed at http://www.carl-acrl.org/Reports/rectoWASC.html. 


\section{FIGURE 3 \\ Student Learning Outcomes and Enabling Outputs with Selected Performance Indicators}

\section{Student Learning Outcomes}

1. All graduates are information literate, prepared to be lifelong learners able to effectively identify, access, and use a variety of information resources; proficient with appropriate information technologies; and able to evaluate and apply information to meet academic, personal, and job-related needs.

\section{Performance Indicators}

a. Description of, number of student participants, and their perceptions of effectiveness and benefits of independent learning opportunities related to information literacy (e.g., locally produced tutorials/instructional software; reference transactions involving substantive teaching; term paper or other individual research advising sessions; training videos; Web-based instruction; printed guides).

b. Documentation of the extent and effects of the integration of library and network resources use within academic programs and across the curriculum. For example, the number, type, and results of information literacy-related degree requirements, course requirements, and assignments in each academic program. Results might include the number of students successfully completing assignments or courses, and actual student performance measures, such as grades, student self-evaluations, search logs/journals, course portfolio scores and tests.

c. Longitudinal data for same sample of students comparing freshmen's or sophomores' rating of their level of confidence about being able to perform specific information literacy skills to that of seniors or recent graduates.

d. Perceptions of recent graduates about how their information literacy skills training/experience from undergraduate study contributes to their success in graduate/professional programs.

e. Success in applying information literacy skills on the job as perceived by alumni and employers.

f. Description of the information literacy program's reach and effects, including measures such as participation rate in formal and informal instruction/orientation; information literacy course completion rate and average grade per FTE student population; and an analysis of curricular penetration based on BI program statistics, student transcript analysis, or syllabi analysis.

g. Student (and for some items faculty and librarian) perceptions of the effects of network use on becoming information literate and academic performance, such as: Has student use of the network affected the quality of papers and projects? If yes, how? Have specific network resources or tools improved one's ability to succeed academically? If yes, which tools/resources, and how?

2. All graduates possess the skills, abilities, attitudes, and knowledge specified in their academic programs.

\section{Enabling Instructional Outputs and Good Practice Criteria}

a. Undergraduate, specifically the general education program, and graduate programs require students to become information literate.

\section{Performance Indicators}

i. See above 1.b.- d., and f.

ii. Copy of undergraduate and graduate catalog or other program documents that specify information literacy requirement.

b. Sufficient and appropriate library, network, and other information and learning resources, equipment, and services are provided and/or made accessible regardless of format or learner's physical location, and integrated into educational programs by required usage in courses across the curriculum.

Performance Indicators 


\section{FIGURE 3 (cont.) \\ Student Learning Outcomes and Enabling Outputs with Selected Performance Indicators}

i. Number of hours students spend studying in the library and/or doing library/networkbased assignments. Data could be organized by academic program and correlated with GPA.

ii. To document access, use, and library infrastructure indicators, see selected performance measures in figure 5 .

c. A computing environment supporting direct-user access for all academic staff and students, regardless of location or time, is effectively operating and reflects service linkages among complementary units providing library, computing, and network services.

\section{Performance Indicators}

i. Data on perceptions of students, faculty, and staff of the effects of network services, such as:

- Has the network changed the way you study, teach, or do your job?

- Has the use of the network affected the quality of learning in the classroom?

- Has the network affected the quality of your mentoring/advising relationship?

- Has the network affected the way you do information retrieval, conduct research, or publish? If yes, how?

ii. Description, use of, and faculty and student evaluations of the benefits of Web-based instruction/training that librarians and others have produced/coproduced.

iii. Perceptions of all campus stakeholders of if and how the network affects institutional image.

iv. Also see selected network access and use measures in figure 5, sections I and II.

d. New knowledge products and other instructional and information technology innovations to improve distance education and on-campus independent and course-related learning have been acquired and/or created locally by collaborations between library and other academic units.

\section{Performance Indicators}

i. See 1.a. above.

ii. Data on the number of products, use statistics, description of relationship to educational goals, and student/faculty perceptions of benefits of electronic or multimedia programs acquired or produced in collaboration with library departments.

iii. Quantitative and qualitative summary of the results of librarian memberships on instructional development/innovation committees and their collaborations with disciplinary faculty and other academic staff, particularly describing products or outcomes related to teaching and learning.

iv. See figure 5, sections I and II for selected access and use measures.

e. The academic environment is conducive to learning and promotes an awareness and appreciation of multicultural diversity.

\section{Performance Indicators}

i. Data on the number of, description of the relationship to institutional goals (e.g., multicultural diversity, study skills) and student/faculty perceptions of benefits of exhibits, programs (lecture or films), multimedia, and Web-based programs acquired or produced/coproduced by library.

ii. Number of minority staff and student workers employed in the library/learning resources units.

iii. Number of hours group study and work spaces are used by students for peer learning and interaction.

iv. See Table 5, section III.B. and C. for indictors to document collections, facilities, and space. Particularly important to students is C.2. and C.3.

f. Effective instructional practices are employed, such as peer group interaction, problem-solving assignments, appropriate use of instructional technology, and other active learning methods that increase the extent and quality of student involvement in learning. 


\section{FIGURE 3 (cont.) \\ Student Learning Outcomes and Enabling Outputs with Selected Performance Indicators}

\section{Performance Indicators}

i. Data from syllabi analysis of types of assignments involving library/Internet research.

ii. Student course evaluation ratings of the use and quality of active learning strategies such as required use of library and network resources, Web-based interactive tutorials, group projects, problem-solving assignments, etc.

iii. Student and faculty ratings of librarian teaching effectiveness.

iv. User survey data on effectiveness of independent learning programs such as audiovisual, multimedia, and Web-based instruction.

v. Number of hours group study and work spaces are used by students for peer learning and interaction.

g. Instructional objectives and student outcomes are clearly specified in academic programs and services so that what students are expected to know and do is evident.

Performance Indicators

i. Copy of the information literacy assessment plan, which includes a description of expected information literacy outcomes/competencies for general education and other academic programs and how competency or proficiency is determined.

ii. Summary of learning objectives for various levels of information literacy instruction, including examples of lesson plans and assignments that specify and illustrate these objectives.

h. Assessment plans, procedures, and processes are in place to evaluate and improve the quality and effectiveness of learning and teaching.

\section{Performance Indicators}

i. Copy of the information literacy assessment plan, which includes performance indicators for measuring student progress and achievement from college entrance/ transfer-in to graduation; demonstrated application of good assessment practices, such as faculty involvement in developing plan; use of multiple methods to gather data; and statement of how assessment results are used for program improvement.

ii. Copy of the library's assessment plan, as well as examples of questionnaire items included in other units' evaluation instruments related to library/network resources and services.

3. Graduates pursuing postbaccalaureate study possess the knowledge and skills to succeed in graduate/professional programs.

\section{Performance Indicators}

a. Survey data of samples of recent graduates about how their information literacy skills training and experience from undergraduate study contribute to their success in graduate/professional programs.

b. Self-report data from graduating seniors rating their perceived ability to apply information literacy skills to graduate study and research.

c. Data from analysis of senior seminar and capstone experiences and portfolios used in specific academic programs.

4. All graduates have the knowledge and skills to conduct an effective job search.

\section{Performance Indicators}

a. Survey data of recent graduates' perceptions of usefulness of job-seeking library and network resources and library sponsored or cosponsored workshops, exhibits, and services.

b. Number, description of, and student perceptions about the benefits of library, computer and related information technology work experience programs, and internships.

c. Number of hits library-maintained Web pages receive dealing with careers and job hunting. 


\section{FIGURE 4}

\section{Other Institutional Outcomes and Outputs to Which Libraries Contribute}

\section{Faculty/Academic Staff Research and Scholarly Productivity and Professional} Development Outcomes

1. Faculty/academic staff are active professionally and contribute to research, scholarly/ creative works, and community service.

\section{Performance Indicators}

a. Data documenting faculty/academic staff perceptions and experiences regarding the effects of network services and resources, such as:

- Has the use of the network affected the quality of teaching material used in the classroom?

- If you depend on the network for your work, for what types of uses do you depend on it?

- Has the network affected the way you do literature searches, conduct research, communicate, or publish? If yes, how?

b. Description, use of, and faculty and student evaluations of the benefits of Web-based and various instructional innovations in which librarians have been involved in the planning, development, or production.

c. Total number of grants secured, publications, presentations, creative works, instructional development projects, and community service projects, with the number and percentage of those benefiting from the use of library and/or network resources and services, such as document delivery/ILL, and reference/research-support services.

d. Summary data of promotion, tenure, and merit awards for librarians, faculty, and other academic staff.

2. Faculty, librarians, and other academic staff maintain excellence in teaching and equivalent academic support roles.

\section{Performance Indicators}

a. Student course evaluation ratings, including the use of active learning strategies, such as required use of library and network resources, group projects, and problem-solving assignments.

b. Student and faculty class evaluations of librarian teaching effectiveness, especially use of active learning strategies.

c. Data on effects of network services on performance, such as selected data for 1.a. above.

d. Description of the faculty/academic staff development program that includes data on the number, type, and attendee perceptions of the quality and benefits of training and other staff development opportunities.

\section{Institutional Viability and Vitality Outcomes and Outputs}

1. Student and staff recruitment and retention rates meet institutional targets and staffing needs.

\section{Performance Indicators}

a. Percentage of new faculty, librarian, and staff hires and new students who indicated that specific library resources and network services affected their decision to come to the institution.

b. Qualitative data describing reasons for student attrition and faculty/staff resignations.

c. Report organized by colleges or academic programs, (including the library) summarizing number, percentage, and race/ethnicity of students (student workers for the library), faculty, librarians, and staff, as well as staffing needs in relation to enrollments and program needs. 


\section{FIGURE 4 (cont.)}

\section{Other Institutional Outcomes and Outputs to Which Libraries Contribute}

2. The campus environment and morale promote operational excellence and effectively support institutional goals.

\section{Enabling Inputs and Outputs}

a. Campus revenue is sufficient to support educational programs and other operations.

Performance Indicators

i. Description of library's success in fund-raising activities and grants.

ii. Data on expenditures connected to academic program benefits, possibly also including costs of unmet demands/needs.

b. The campus governance structure includes appropriate staff and students in its committee memberships and contributes significantly to campus programs and services.

\section{Performance Indicator}

i. Quantitative and qualitative summary of the results of librarians' memberships on campus committees and their collaborations with faculty and other academic staff, particularly describing products or outcomes relating to teaching, student services, collection development, information technology planning, and assessment.

c. Institutional units cooperate and the institution collaborates, as appropriate, with neighboring $\mathrm{K}-12$ schools, community colleges, and other organizations to improve education at all levels.

\section{Performance Indicator}

i. Copies of cooperative resource-sharing agreements and contracts, as well as other cooperative agreements, including documentation of the benefits to students and the cooperating units.

d. A computing environment supporting direct-user access for all academic staff, regardless of location or time, is effectively operating and reflects formalized service linkages among complementary units to support teaching, research, and administrative functions. Performance Indicators

i. Perceptions of all campus stakeholders of how the network affects campus operations and institutional image.

ii. Description of computing/network environment focusing on use statistics, benefits, and service linkages

e. Campuswide assessment plans and procedures, developed by appropriate segments of the institution, are effectively employed to advance institutional goals and objectives.

\section{Performance Indicator}

i. Copy of the library's assessment plan(s), which includes demonstrated application of good assessment practices as well as examples of questionnaire items included in other campus units' evaluation instruments related to library and network resources and services.

f. The faculty and staff professional development program is operating effectively.

\section{Performance Indicator}

i. Description of the faculty/staff development program, which includes data on the number, type, and attendee perceptions of the quality and benefits of training and other staff development opportunities. 


\section{FIGURE 5 \\ Access, Availability, Use and Infrastructure Measures (Input and Output Measures)}

\section{Access and Availability Measures}

(Where applicable, provide data separately for off-campus access/distance learners.)

1. Proportion of collections/materials listed in OPAC.

2. Extent and ease of access to library catalogs and databases for all campus constituents, but particularly distance learners.

3. User satisfaction/success rate in finding and obtaining materials.

4. ILL/document delivery fill rate and turnaround time.

5. Description and results of cooperative resource-sharing agreements and contracts with external information and document providers, including the benefits to students and cooperating units.

6. Speed of recall for items on loan requested by other users.

7. Match of hours open and electronic resources and services availability with user needs.

8. Speed and accuracy of reshelving of materials.

9. Description of how disabled users can access library resources.

\section{Use Measures}

(Includes reference and other user assistance services that facilitate use.)

1. Number of remote and nonremote log-ins to OPAC and other networked resources per capita.

2. Number of searches from remote and nonremote terminals per capita.

3. Number of hits library-maintained Web pages receive.

4. Number and/or percentages of faculty, students, staff visiting library-produced parts of the CWIS.

5. Entrance gate counts per FTE and/or number of sign-ups for group study rooms.

6. Number of courses and students by academic program requiring use of library and network resources.

7. Circulation and in-house use of collections per FTE user and organized by academic program/major and user category.

8. Number of instructional software items delivered or charged out to faculty for classroom use in proportion to faculty population by academic program.

9. User satisfaction with use of selected materials, services, and facilities.

10. User satisfaction with availability and quality of reference assistance.

\section{Infrastructure Measures}

A. Human \& Fiscal

1. Number of professional staff and how they are deployed to support campus and library mission and goals (could include comparisons to peer institutions and/or ACRL standards).

2. Ratio of reference and instruction/training services staff to users and/or potential users (could include data documenting unfilled training demand).

3. Expenditures connected to academic program benefits, documenting costs of unmet demand/need. 


\section{FIGURE 5 (cont.) \\ Access, Availability, Use and Infrastructure Measures \\ (Input and Output Measures)}

B. Quality of Collections and Learning Resources (See also relevant measures in I and II above)

1. Statistics, organized wherever possible by academic program or broad discipline, of the number of locally held or accessible collections and learning resources, and a description and assessment of how these support the curricular, cocurricular, and faculty research needs.

2. Currency of materials for specific academic programs.

3. Provision of multiple copies of high use items.

4. Flexibility of budget to respond to new subject areas.

5. Adequacy of library collections compared to peer institutions.

6. Description and results of periodic collection evaluations.

C. Facilities/Equipment

1. Description of extent of campus network and its components; number of public access stations; number and percentage of classrooms, student labs, residence halls, and faculty offices that have access to campus network; and number of dial-in and other access modes for off-campus students and staff.

2. User perceptions of the quietness of the study environment.

3. Number of seats and group study/workrooms per FTE and stakeholder perceptions about adequacy of such space.

4. Documentation on equipment (e.g., photocopiers, computer workstations) replacement and maintenance, along with user satisfaction ratings. 